\title{
Study on the Corrosion Inhibition Characteristic of ZH and ZG Mannich Base Inhibitors
}

\author{
Shusheng Zhou, Kehua Li*, Tiantian Tang, Dongpo Shi \\ School of Chemistry and Environmental Engineering, Yangtze University, Jingzhou, China \\ Email: *likehua01@163.com
}

How to cite this paper: Zhou, S.S., Li, K.H., Tang, T.T. and Shi, D.P. (2017) Study on the Corrosion Inhibition Characteristic of ZH and ZG Mannich Base Inhibitors. Open Journal of Yangtze Gas and Oil, 2, 151-160.

https://doi.org/10.4236/ojogas.2017.23011

Received: March 9, 2017

Accepted: July 11, 2017

Published: July 14, 2017

Copyright (c) 2017 by authors and Scientific Research Publishing Inc. This work is licensed under the Creative Commons Attribution International License (CC BY 4.0).

http://creativecommons.org/licenses/by/4.0/

\begin{abstract}
ZG/ZH Mannich bases (acid corrosion inhibitors) were synthesized with benzaldehyde, 2-aminothiazole, acetophenone/cyclohexanone as raw materials, and selecting the appropriate proportion of reaction time, temperature and ratio of raw materials.The corrosion inhibition performance of two kinds of Mannich bases on N80 steel was investigated by means of mass loss method and electrochemical technique. The result of mass loss method showed that two kinds of inhibitors both had excellent effect on N80 steel in 15\% hydrochloric acid solution. Electrochemical technique showed that both ZG and ZH were a mainly anodic-controlling composite corrosion inhibitor, and their corrosion inhibition effect was further confirmed by AC impedance technique. The adsorption behavior between inhibitiors and the steel surface both abides by the Langmuir isotherm model.
\end{abstract}

\section{Keywords}

Thiazole, Corrosion Inhibitor, Inhibition Mechanism, Adsorption, Mannich Base

\section{Introduction}

Mild steel is one of the most extensively used constructional materials in industries due to its low cost and prominent mechanical properties. However, mild steel is easily eroded in the process of dealing with it such as acid cleaning, pickling and so on [1] [2]. In order to solve this problem, it is strongly necessary to add an inhibitor to protect mild steel from corrosion [3] [4]. Adding anti-corrosion inhibitor is relatively simple, efficient and economic approach to protect metals in acid media [5] [6] [7] [8] [9].

The Mannich bases are famous acid inhibitors containing $\mathrm{N}, \mathrm{O}$ and $\mathrm{S}$ atoms, and these atoms of high electron density generate multiple bonds through which they are adsorbed on metal surface, preventing corrosion reaction of N80 steel 
from acid media. The polar functional groups are commonly viewed as the reaction center for the establishment of the adsorption process [10] [11] [12] [13]. The Mannich base acts as a corrosion inhibitor due to the presence of the hetero atoms. The Mannich reaction is a three component condensation reaction in which an active $\mathrm{H}$ atom is allowed to react with an aldehyde or ketone and amine, concomitant release of water to produce a new base known as a Mannich base. On the basis of two new-type of synthesized acid corrosion inhibitors via mannich reaction, its reaction condition-reaction temperature may be less than $100^{\circ} \mathrm{C}$, and reaction pressure in room may not need to change, and reaction time may be transient-can get moderate. In general, containing more than three phenyl rings, the large molecule of synthesized compound has poor performance of water solubility. With the increase of phenyl ring, the water solubility of compound decreases obviously. Molecules of corrosion inhibitors in this paper include not more than two phenyl rings, and both of corrosion inhibitors can dissolve easily in water. Raw materials of synthesized ZG/ZH Mannich bases perform excellent inhibition efficiency respectively, due to containing $\mathrm{O}$ or Cyclobenzene. 2-aminothiazole is a kind of excellent traditional corrosion inhibitor, and contains $\mathrm{N}$ and $\mathrm{S}$ atoms. 2-aminothiazole was modified as acid corrosion inhibitors by mannich reaction. ZG/ZH Mannich bases were synthesized with benzaldehyde, 2-aminothiazole, acetophenone/cyclohexanone as raw materials. The corrosion inhibition performance of two kinds of Mannich bases on N80 steel was studied by means of mass loss method and electrochemical technique. In view of structures and performances of corrosion inhibitors, author can get more research about corrosion.

\section{Experimental}

Materials. N80 steel sheets were pretreated by grinding with abrasive paper then cleaned with double-distilled water, degreased with acetone and dried at room temperature before doing the experiment. The way of preparing $15 \%$ hydrochloric acid is diluting of analytical grade $37 \% \mathrm{HCl}$ with distilled water.

Inhibitors. ZG/ZH Mannich bases (acid corrosion inhibitors) were synthesized with benzaldehyde, acetone, aniline/benzylamine as raw materials. Appropriate proportion of reaction time, temperature and ratio of raw materials were selected. The molecular structure of studied compounds were given as Scheme 1, Scheme 2.

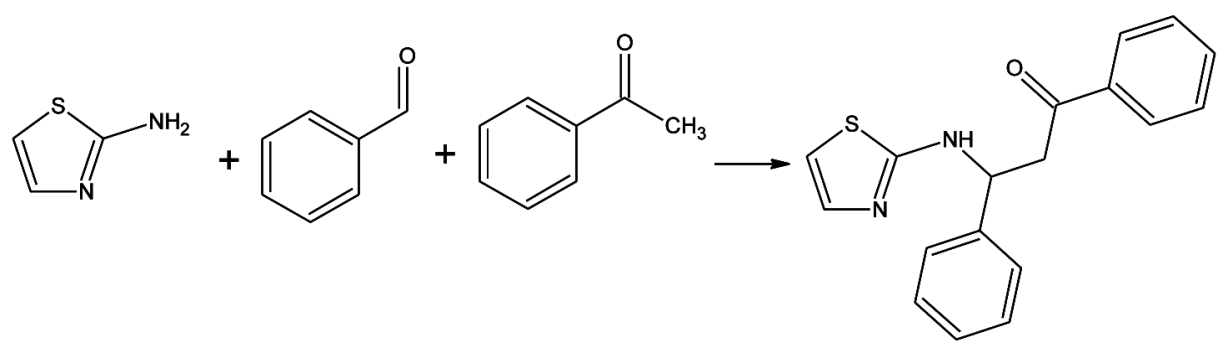

Scheme 1. Structure and synthetic route of ZG. 


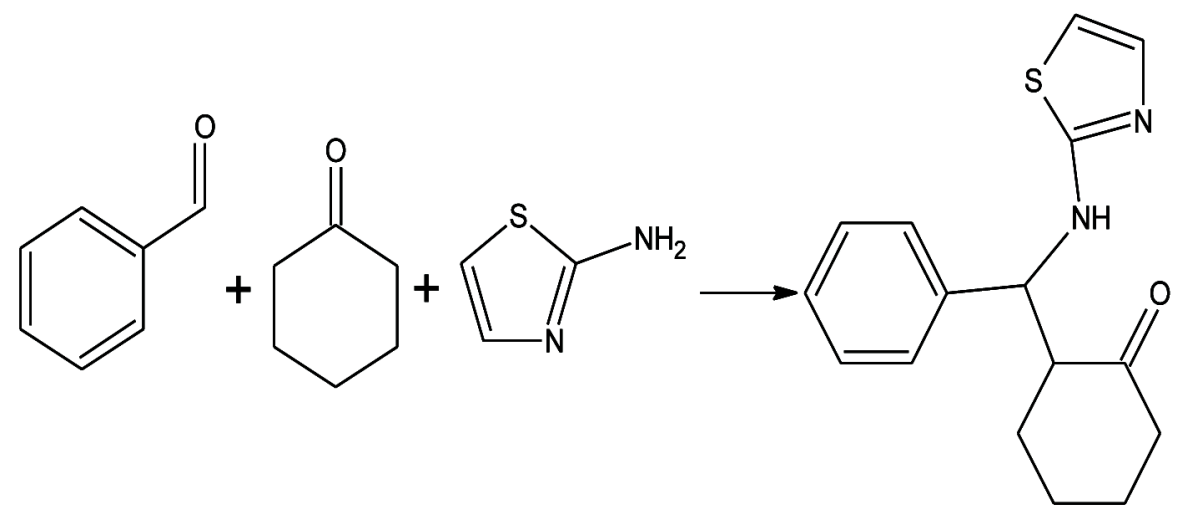

Scheme 2. Structure and synthetic route of $\mathrm{ZH}$.

\subsection{Weight Loss Method}

Weight loss experiments were carried out in accordance with the standard of SY5405-1996. All the tests were done in aerated $15 \% \mathrm{HCl}$.

The corrosion rate $(v)$ in $\mathrm{g} \cdot \mathrm{m}^{-2} \cdot \mathrm{h}^{-1}$ was determined from the following relationship:

$$
v=\frac{W_{0}-W}{S t}
$$

where $W$ and $W_{0}$ are the weight loss in the presence and absence of inhibitors, $t$ is the corrosion time (h), and $S$ is the area of specimen $\left(\mathrm{m}^{2}\right)$.

The inhibition efficiency $(\eta)$ was determined from the following relationship:

$$
\eta=\frac{v_{0}-v}{v_{0}} \times 100 \%
$$

where, $V$ and $V_{0}$ are the corrosion rates of the N80 steel in the presence and absence of inhibitors

\subsection{Electrochemical Studies}

Electrochemical Impedance (EI) and Tafel polarization were conducted in aerated $15 \% \mathrm{HCl}$ in $\mathrm{CHI} 660 \mathrm{E}$ electrochemical work station at room temperature. A conventional three-electrode system [14] consisting of platinum as counter electrode, a saturated calomel electrode as reference electrode, and N80 steel as working electrode were used. The EI measurements were acquired at a corrosion potential over a frequencyrange of $0.1 \sim 100 \mathrm{kHz}$ with signal amplitude of $5 \mathrm{mV}$. The Tafel polarization measurements were conducted for a potential range of $-300 \mathrm{mV}$ to $-600 \mathrm{mV}$ with respect to open circuit potential, at a scan rate of 1 $\mathrm{mV} \cdot \mathrm{s}^{-1}$.

\section{Results and Discussion}

\subsection{Mass Loss Studies}

The corrosion rates of different concentrations of inhibitor $\mathrm{ZG} / \mathrm{ZH}$ in $15 \%$ hydrochloric acid for an exposure time $4 \mathrm{~h}$ at $60^{\circ} \mathrm{C}$ are presented in Figure 1. 


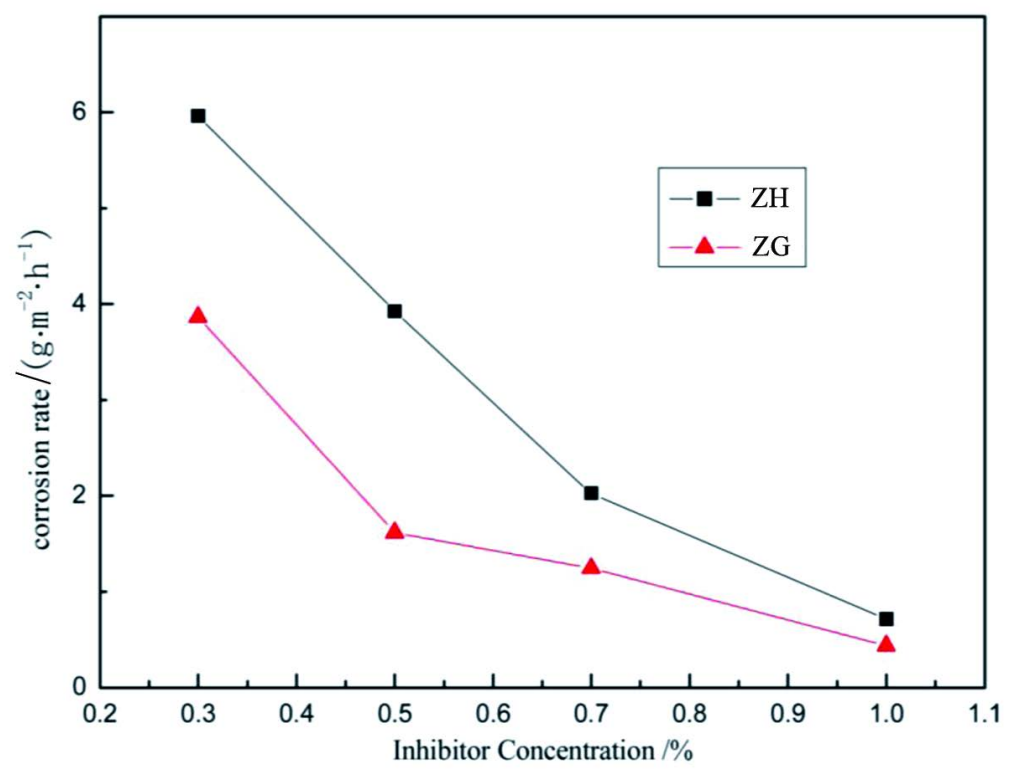

Figure 1. The corrosion rate of different concentrations of ZH/ZG in $15 \%$ hydrochloric acid.

The results indicated that the corrosion rates of $\mathrm{N} 80$ steel in $15 \%$ hydrochloric acid were $0.4362 \mathrm{~g} \cdot \mathrm{m}^{-2} \cdot \mathrm{h}^{-1}$ of inhibitor ZG and $0.7118 \mathrm{~g} \cdot \mathrm{m}^{-2} \cdot \mathrm{h}^{-1}$ of inhibitor ZH when the dosage of inhibitor added respectively was $1.0 \%$, which is much higher than national standard. With increase of concentrations of inhibitor ZG/ZH, the corrosion rate of $\mathrm{N} 80$ steel in $15 \%$ hydrochloric acid decreases respectively, and they prevent effectively the metal surface from water and corrosive medium in the liquid [15].

\subsection{Electrochemical Studies}

Polarization studies. Tafel polarization for N80 steel in 15\% hydrochloric acid in the obsence and presence of different concentration of inhibitor ZG, inhibitor $\mathrm{ZH}$ at room temperature are shown in Figure 2.

Figure 2 represents the polarization curves of $\mathrm{N} 80$ steel in $15 \% \mathrm{HCl}$ in the absence and presence of various concentrations of ZG and ZH. It can be seen from Figure 2 that, in the presence of inhibitors, the curves are shifted to lower current regions, showing the inhibition tendency of the Mannich bases. There was definite trend observed in the $E_{\text {corr }}$ values in the presence of both the Mannich bases. In the present study, shift in $E_{\text {corr }}$ values is in the range of 0.010 0.030 V suggesting that they all act as mixed type inhibitors.

The values of various electrochemical parameters derived by Tafel polarization of the inhibitors are given in Table 1. Investigation Table 1 revealed that the values of ba increase orderly in the presence of both the inhibitors, indicating that both anodic and cathodic reactions are affected but the effect on the anodic reactions is more prominent. Thus, both ZG and ZH acted as mainly anodiccontrolling composite corrosion inhibitors [16]. In the same circumstances, according to Icorr, ZG has higher inhibition efficiency than that of ZH. 

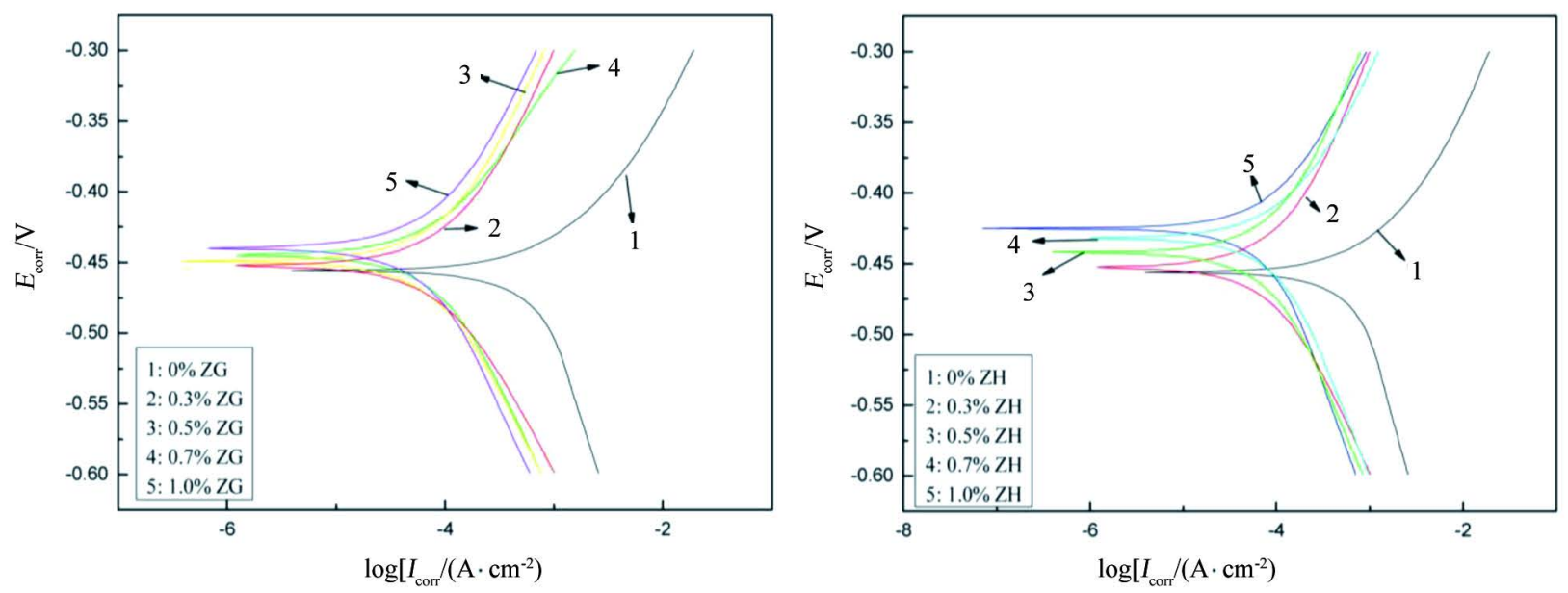

Figure 2. Polarization curves of N80 steel with different concentrations of ZH/ZG inhibitor.

Table 1. The electrochemical parameters for N80 with different concentrations ZG/ZH inhibitor.

\begin{tabular}{cccccc}
\hline inhibitor & Conc. & $\mathrm{E}_{\text {corr }} / \mathrm{v}$ & $\mathrm{I}_{\text {corr }} /\left(\mathrm{A} \cdot \mathrm{cm}^{-2}\right)$ & $\mathrm{B}_{\mathrm{a}} /\left({\left.\mathrm{mv} \cdot \mathrm{dec}^{-1}\right)}^{-3} \mathrm{~B}_{\mathrm{c}} /\left(\mathrm{mV} \cdot \mathrm{dec}^{-1}\right)\right.$ \\
\hline blank & $15 \% \mathrm{HCl}$ & -0.456 & $1.074 \times 10^{-3}$ & 6.566 & 4.083 \\
& $0.3 \%$ & -0.452 & $1.000 \times 10^{-4}$ & 6.914 & 6.743 \\
\multirow{2}{*}{ ZG } & $0.5 \%$ & -0.449 & $9.218 . \times 10^{-5}$ & 7.034 & 5.030. \\
& $0.7 \%$ & -0.447 & $9.088 \times 10^{-5}$ & 7.195 & 5.666 \\
& $1.0 \%$ & -0.440 & $8.419 \times 10^{-5}$ & 8.890 & 6.218 \\
& $0.3 \%$ & -0.451 & $1.147 \times 10^{-4}$ & 6.740 & 6.338 \\
\multirow{2}{*}{$\mathrm{ZH}$} & $0.5 \%$ & -0.442 & $1.069 \times 10^{-4}$ & 7.034 & 7.743 \\
& $0.7 \%$ & -0.432 & $9.938 \times 10^{-5}$ & 6.906 & 6.794 \\
& $1.0 \%$ & -0.425 & $9.933 . \times 10^{-5}$ & 8.345 & 5.653 \\
\hline
\end{tabular}

\subsection{AC Impedance Studies}

Nyquist plots of N80 steel plate in 15\% hydrochloric acid in the obsence and presence of different concentration of inhibitor $\mathrm{ZG}$, inhibitor $\mathrm{ZH}$ at room temperature are presented in Figure 3.
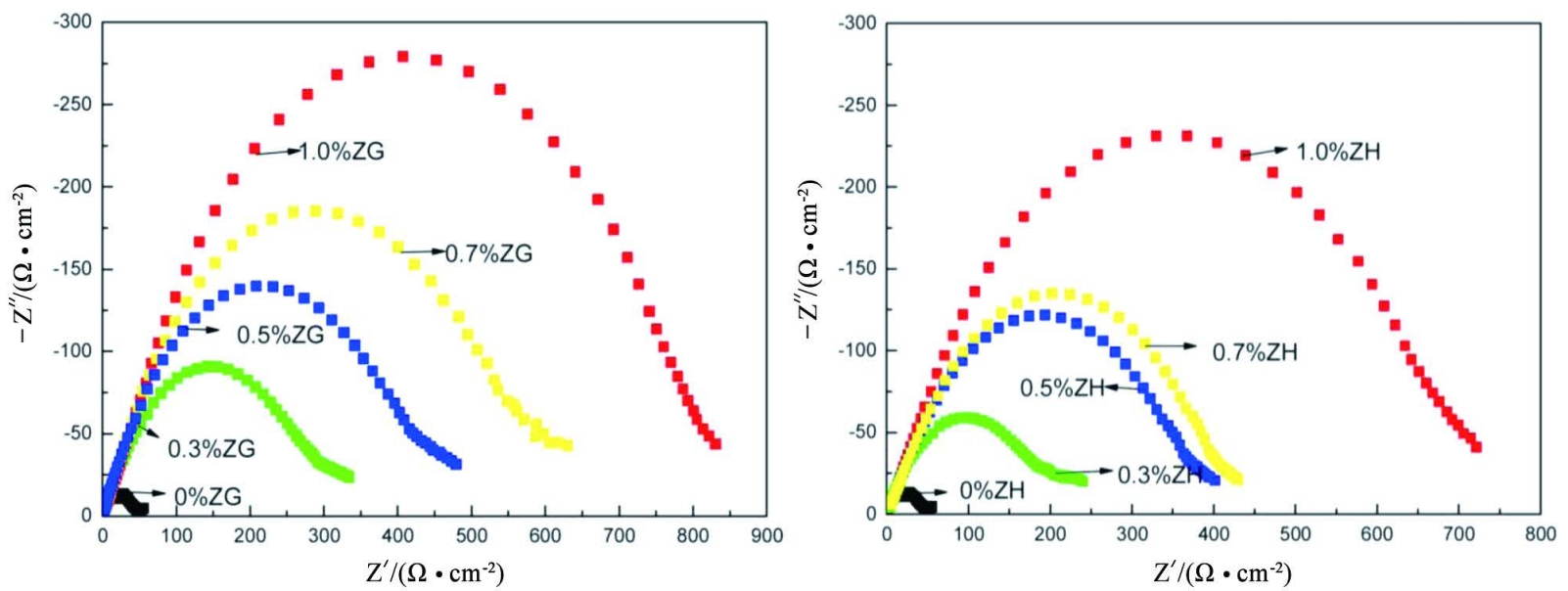

Figure 3. The Nyquist figure of N80 steel with different concentrations of ZG/ZH inhibitor. 
Impedance parameters can be calculated from Nyquist plot via equivalent circuit to fit the impedance data, which are presented in Figure 4.

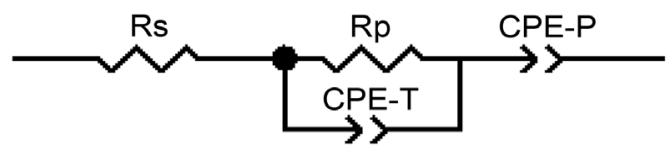

Figure 4. Equivalent circuit to fit the impedance data.

The corrosion of $\mathrm{N} 80$ steel in $15 \% \mathrm{HCl}$ solution in the absence and presence of ZG and ZH were investigated by EI. Nyquist plots for N80 steel obtained at the interface in the absence and presence of inhibitors at different concentrations are given in Figure 3.

The Nyquist diagram obtained with $15 \% \mathrm{HCl}$ shows only one capacitive loop and the diameter of the semicircle increases on increasing the inhibitor concentration suggesting that the formed inhibitive film was strengthened by the addition of inhibitors. All the main parameters deduced from the impedance technique are given in Table 2.

Table 2. The AC impedance coefficient during the corrosion process.

\begin{tabular}{cccccc}
\hline inhibitor & Conc. & $\mathrm{Rs} /\left(\Omega \cdot \mathrm{cm}^{-2}\right)$ & $\mathrm{CPE}-\mathrm{T} /\left(\mathrm{F} \cdot \mathrm{cm}^{-2}\right)$ & $\mathrm{CPE}-\mathrm{P} / 1$ & $\mathrm{Rp} /\left(\Omega \cdot \mathrm{cm}^{-2}\right)$ \\
\hline blank & $15 \% \mathrm{HCl}$ & 0.658 & $1.92 \times 10^{-4}$ & 0.64114 & 46.2 \\
& $0.3 \%$ & 1.024 & $1.25 \times 10^{-4}$ & 0.66755 & 332.7 \\
$\mathrm{ZG}$ & $0.5 \%$ & 1.463 & $1.09 \times 10^{-4}$ & 0.69163 & 557.9 \\
& $0.7 \%$ & 2.513 & $1.12 \times 10^{-4}$ & 0.69627 & 733.5 \\
& $1.0 \%$ & 2.928 & $1.05 \times 10^{-4}$ & 0.69231 & 809.9. \\
& $0.3 \%$ & 0.799 & $1.42 \times 10^{-4}$ & 0.66957 & 213.3 \\
$\mathrm{ZH}$ & $0.5 \%$ & 2.157 & $1.17 \times 10^{-4}$ & 0.67694 & 395.4 \\
& $0.7 \%$ & 2.626 & $1.13 \times 10^{-4}$ & 0.67581 & 431.7 \\
& $1.0 \%$ & 2.513 & $1.08 \times 10^{-4}$ & 0.69627 & 733.5 \\
\hline
\end{tabular}

\subsection{Analysis of Adsorption Mechanism}

Adsorption isotherm. Surface coverage $(\theta)$ was regarded as $\eta$ nearly and was tested by mass loss method in 15\% hydrochloric acid in accordance with the standard of SY5405-1996.

The values of the concentration of inhibitor (c) and $\theta$ were evaluated by conforming to various isotherms like Bockris-Swinkels [17], Langmuir [18] and Frumkin [19]. However, in this experiment the best fit was subject to Langmuir adsorption isotherm as presented in Figure 5.

Langmuir adsorption isotherm $K \mathrm{c}=\theta /(1-\theta)$

The relationship can be changed to: $c / \eta=c+1 / K$

where, $K$ is the equilibrium constant for the process of desorption/adsorption. 


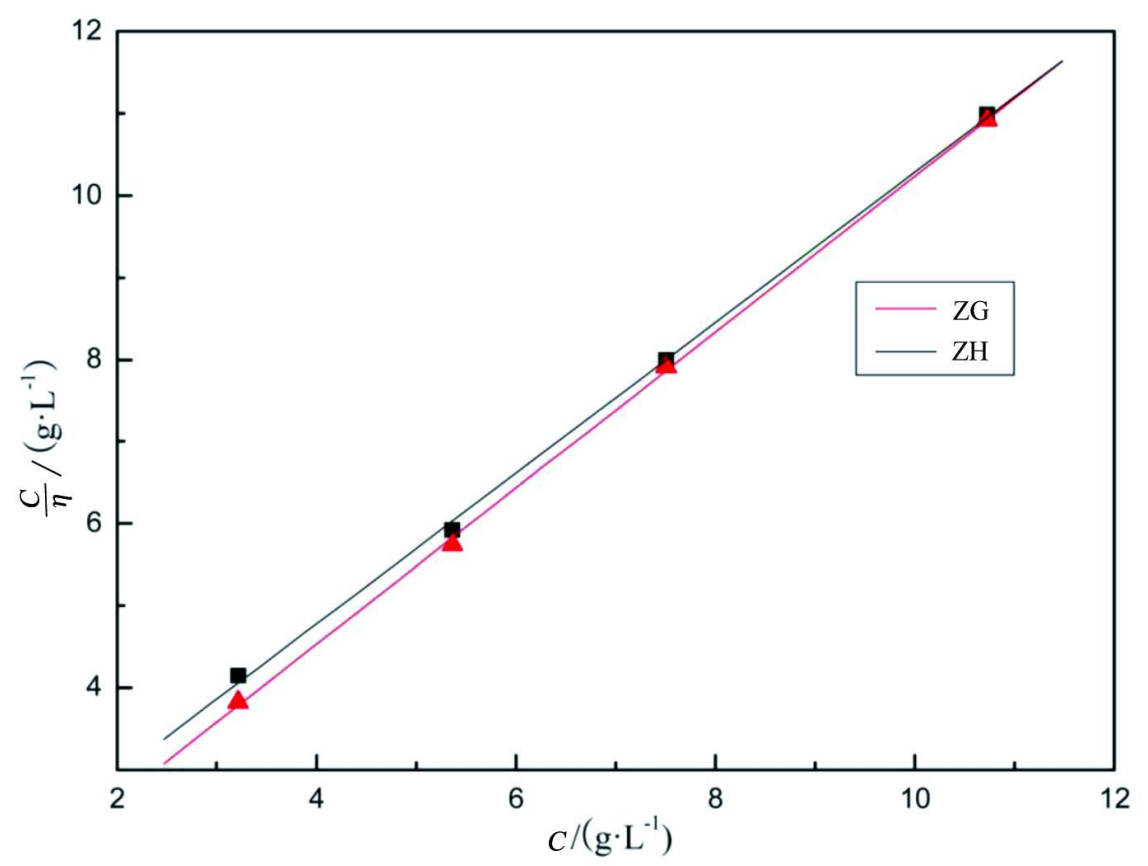

Figure 5. Adsorption isotherm of ZH/ZG inhibitor.

According to Figure 5, The plot of $c$ against $c / \eta$ was nearly a straight line. It expressed that inhibitor formed a monolayer adsorption on N80 steel. $\mathrm{K}$ can be calculated which is related to free energy of adsorption, $\Delta G_{\mathrm{m}}$, as given by following equation:

$$
K=\frac{1}{C_{\text {solvent }}} \exp \left(\frac{-\Delta G_{\mathrm{m}}}{R T}\right)
$$

where $C_{\text {solvent }}$ is concentration of water in solution, is $55.5 \mathrm{~mol} / \mathrm{L}, R=8.314$ $\left(\mathrm{J} \cdot \mathrm{mol}^{-1} \cdot \mathrm{K}^{-1}\right)$.

Thermodynamic parameters for the adsorption of inhibitors in $15 \% \mathrm{HCl}$ on the N80 steel at $60^{\circ} \mathrm{C}$ was given in Table 3 .

Table 3. The thermodynamic parameters of the adsorption process.

\begin{tabular}{cccc}
\hline inhibitor & $\mathrm{R}^{2} / 1$ & $K_{\text {ads }} /\left(\mathrm{L} \cdot \mathrm{mol}^{-1}\right)$ & $\square \mathrm{G}_{\text {ads }}^{\theta} /\left(\mathrm{kJ} \cdot \mathrm{mol}^{-1}\right)$ \\
\hline ZG & 0.09993 & 1.3746 & -13.25 \\
ZH & 0.09998 & 0.9018 & -12.50 \\
\hline
\end{tabular}

The negative value of $\Delta G \mathrm{~m}$ suggests that inhibitor molecules are spontaneously adsorbed on steel surface. More negative $\Delta G_{m}$ means more the strength of adsorption. It accepted that the values of $\Delta G_{m}$ up to $-20 \mathrm{~kJ} \cdot \mathrm{mol}^{-1}$, the types of adsorption were regarded as physisorption, while the values around $-40 \mathrm{~kJ} \cdot \mathrm{mol}^{-1}$ or smaller, were seen as chemisorptions. In this study the value of $\Delta G_{m}$ was up to $-20 \mathrm{~kJ} \cdot \mathrm{mol}^{-1}$, which means the possibility of both physisorption.

Effect of temperature. The effect of temperature on the performance of the inhibitors for $\mathrm{N} 80$ steel plate in $15 \%$ hydrochloric acid at $20^{\circ} \mathrm{C}, 40^{\circ} \mathrm{C}, 60^{\circ} \mathrm{C}, 80^{\circ} \mathrm{C}$ was researched using weight loss methods, when the dosage of inhibitor added 
was $1.0 \%$. The apparent activation energy $(\mathrm{Ea})$ for the corrosion reaction of $\mathrm{N} 80$ steel in 15\% hydrochloric acid can be calculated from Arrhenius equation [20]:

$$
\text { Vcorr }=A \exp (-E a / R T)
$$

The relationship can be changed to: $\ln V$ corr $=-E a / R T+\ln A$

where $A$ is the Arrhenius pre-exponential constant. Plots of ln Vcorr against 1/T are shown in Figure 6.

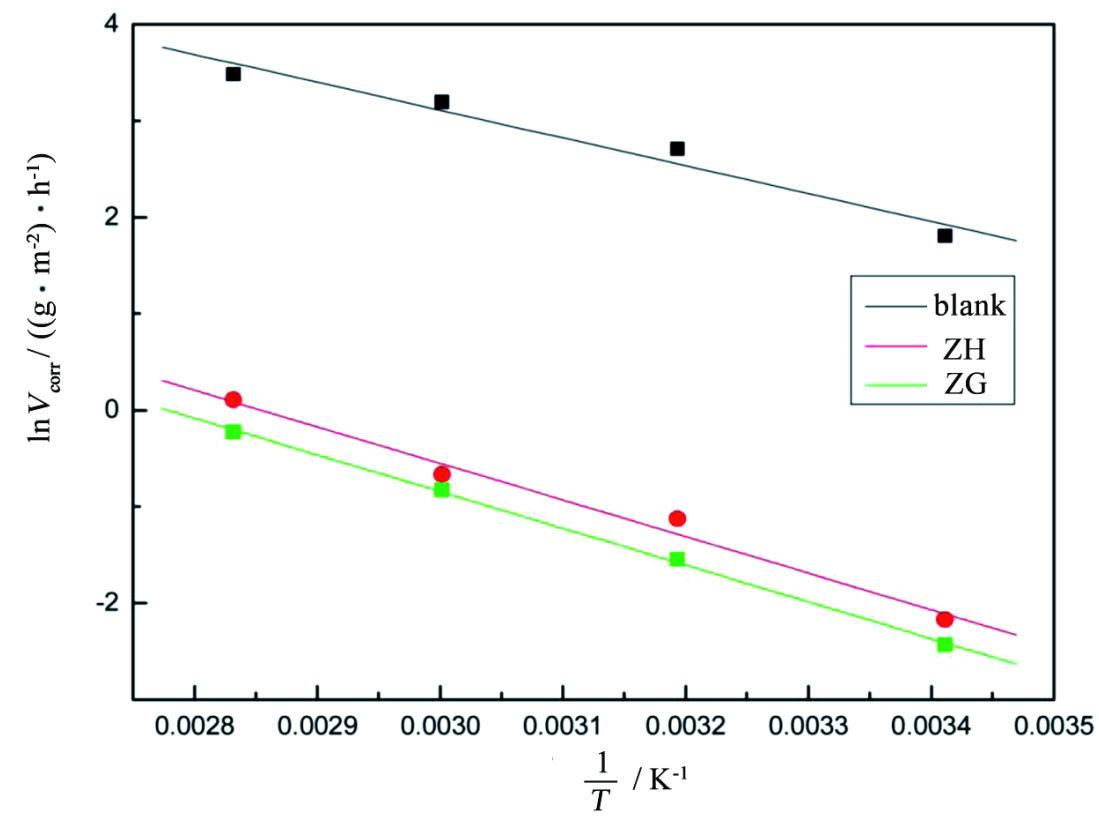

Figure 6. The Arrhenius curve of $\mathrm{ZH} / \mathrm{ZG}$ inhibitor.

According to Figure 6, the value of Ea of the corrosion reaction of N80 steel in $15 \%$ hydrochloric acid in the obsence of inhibitor was $23.986 \mathrm{KJ} / \mathrm{mol}$. Adding the inhibitors $\mathrm{ZG} / \mathrm{ZH}$ makes the values of $E a$ of the corrosion reaction more than $30 \mathrm{KJ} / \mathrm{mol}$. and makes corrosion rate of N80 steel decreased sharply.

\section{Conclusions}

1) $\mathrm{ZG} / \mathrm{ZH}$ Mannich bases were synthesized with benzaldehyde, 2-aminothiazole, acetophenone/cyclohexanone as raw materials, and the corrosion rate of N80 steel in 15\% hydrochloric acid was much higher than national standard respectively when the dosage of inhibitor added was $1.0 \%$.

2) The negative value of $\Delta G_{\mathrm{m}}$ obtained from this study indicated that these compounds are absorbed spontaneously on the N80 steel surface.

3) The absorption of $\mathrm{ZG} / \mathrm{ZH}$ inhibitor was subjected to Langmuir absorption isotherm.

4) Electrochemical technique showed that both $\mathrm{ZG}$ and $\mathrm{ZH}$ act as a mainly anodic-controlling composite corrosion inhibitors, and ZG has higher inhibition efficiency than that of $\mathrm{ZH}$, which accorded well with results of Weight loss studies. 


\section{Acknowledgements}

Thanking Zhou Shu-sheng, Tang Tian-tian and Shi Dong-po for their assistance. and the research was supported by two Fund project: National natural science foundation (41202111) and Hubei provincial department of education science and technology research project (B2016445).

\section{References}

[1] Bahrami, M.J., Hosseini, S.M.A. and Pilvar, P. (2010) Experimental Andtheoretical Investigation of Organic Compounds as Inhibitors for Mild Steel Corrosion in Sulfuric Acid Medium. Corrosion Science, 52, 2793-2803.

https://doi.org/10.1016/j.corsci.2010.04.024

[2] Jia, Y.Z., Wang, J.Q., Han, E.H. and Ke, W. (2011) Stress Corrosion Cracking of X80 Pipeline Steel in Near-Neutral pH Environment under Constant Load Tests with and without Preload. Journal of Materials Science \& Technology, 27, 10391046. https://doi.org/10.1016/S1005-0302(11)60184-9

[3] Fu, J.J., Li, S.N., Wang, Y., et al. (2011) Computational and Electrochemical Studies on the Inhibition of Corrosion of Mild Steel by L-Cysteine and Its Derivatives. Journal of Materials Science, 46, 3550-3559. https://doi.org/10.1007/s10853-011-5267-4

[4] Ali, S.A., Saeed, M.T. and Rahman, S.U. (2003) The Isoxazolidines: A New Class of Corrosion Inhibitors of Mild Steel in Acidic Medium. Corrosion Science, 45, 253266. https://doi.org/10.1016/S0010-938X(02)00099-9

[5] Elewady, G.Y. and Motafa, H.A. (2009) Ketonic Secondary Mannich Base as Corrosion Inhibitors for Aluminium. Desalination, 247, 573-582. https://doi.org/10.1016/j.desal.2008.08.006

[6] Ahamad, I., Prasad, R. and Quraishi, M.A. (2010) Adsorption and Inhibitive Properties of Some New Mannich Base of Isatin Derivatives on Corrosion of Mild Steel in Acidic Media. Corrosion Science, 52, 1472-1481. https://doi.org/10.1016/j.corsci.2010.01.015

[7] Singh, A.K. and Quraishi, M.A. (2010) The Effect of Some Bis-Thiadiazole Derivatives on the Corrosion of Mild Steel in Hydrochloricacid. Corrosion Science, 52, 1373-1385. https://doi.org/10.1016/j.corsci.2010.01.007

[8] Vishwanatham, S. and Haldar, N. (2008) Furfuryl Alcohol as Corrosion Inhibitor for N80 Steel in Hydrochloric Acid. Corrosion Science, 50, 2999-3004. https://doi.org/10.1016/j.corsci.2008.08.005

[9] Aiad, I.A., Hafiz, A., El-Awady, M.Y. and Hbib, A.O. (2010) Some Imidazoline Derivatives as Corrosion Inbnibitors. Journal of Surfactants and Detergents, 13, 247-254. https://doi.org/10.1007/s11743-009-1168-9

[10] El Sayed, H.E.A., El Ahmed, N., Sami, A.E., et al. (2006) Corrosion Inhibitors Part II: Quantumchemical Studies on the Corrosion Inhibitions of Steel Inacidic Medium by Some Triazole, Oxadiazole and Thiadiazole Derivatives. Electrochimica Acta, 51, 3957.

[11] Ali, S.A., Al-Muallem, H.A., Saeed, M.T., et al. (2008) Hydrophobic Tailed Bicycloisoxazolidines: A Comparative Study of the Newly Synthesized Compounds on the Inhibition of Mild Steel Corrosion in Hydrochloric and Sulfuric Acid Media. Corrosion Science, 50, 664-675. https://doi.org/10.1016/j.corsci.2007.10.010

[12] Singh, A.K. and Quraishi, M.A. (2010) Inhibiting Effects of 5-SubstitutedisatinBased Mannich Bases on the Corrosion of Mild Steel in Hydrochloric Acid Solution. 
Journal of Applied Electrochemistry, 40, 1293-1306. https://doi.org/10.1007/s10800-010-0079-9

[13] Ali, S.A., Saeed, M.T. and Rahman, S.U. (2003) The Isoxazolidines: A New Class of Corrosion Inhibitors of Mild Steel in Acidic Medium. Corrosion Science, 45, 253 266. https://doi.org/10.1016/S0010-938X(02)00099-9

[14] Cao, C.N. (2008) Corrosion Electrochemical Principles. 211-212.

[15] Ahamad, I., Gupta, C., Prasad, R. and Quraishi, M.A. (2010) An Experimental and Theoretical Investigation of Adsorption Characteristics of a Schiff Base Compound as Corrosion Inhibitor at Mild Steel/Hydrochloric Acid Interface. Journal of Applied Electrochemistry, 40, 2171-2183. https://doi.org/10.1007/s10800-010-0199-2

[16] Chandra, B.V., Quraishi, M.A. and Ambrish, S. (2015) 2-Aminobenzene-1, 3-Dicarbonitriles as Green Corrosion Inhibitor for Mild Steel in $1 \mathrm{M} \mathrm{HCl}$ : Electrochemical, Thermodynamic, Surface and Quantum Chemical Investigation. Journal of the Taiwan Institute of Chemical Engineers, 49, 229-239. https://doi.org/10.1016/j.jtice.2014.11.029

[17] Johnson, W., Wroblowa, H. and Bockris, J.O.M. (1994) The Mechanism of the Electrochemical Oxidation of Oxalic Acid. Electrochemical Society, 9, 639-651.

[18] Alberty, R.A. (1993) Thermodynamics of Reactions of Nicotinamide Adenine Dinucleotide and Nicotinamide Adenine Dinucleotide Phosphate. Biochemistry and BioPhysics, 307, 8-14. https://doi.org/10.1006/abbi.1993.1552

[19] Gileadi, E. and Kirowa-Eisner, E. (2005) Some Observations Concerning the Tafel Equation and Its Relevance Tocharge Transfer in Corrosion. Corrosion Science, 47, 3068-3085. https://doi.org/10.1016/j.corsci.2005.05.044

[20] Li, X.H., Deng, S.D. and Fu, H. (2012) Inhibition of the Corrosion of Steel in HCl, $\mathrm{H}_{2} \mathrm{SO}_{4}$ Solutions by Bamboo Leaf Extract. Corrosion Science, 62, 163-175. https://doi.org/10.1016/j.corsci.2012.05.008

\section{Scientific Research Publishing}

Submit or recommend next manuscript to SCIRP and we will provide best service for you:

Accepting pre-submission inquiries through Email, Facebook, LinkedIn, Twitter, etc. A wide selection of journals (inclusive of 9 subjects, more than 200 journals)

Providing 24-hour high-quality service

User-friendly online submission system

Fair and swift peer-review system

Efficient typesetting and proofreading procedure

Display of the result of downloads and visits, as well as the number of cited articles

Maximum dissemination of your research work

Submit your manuscript at: http://papersubmission.scirp.org/

Or contact ojogas@scirp.org 